Biological and Applied Sciences

Vol.59: e16160470, January-December 2016 35http://dx.doi.org/10.1590/1678-4324-2016160470 ISSN 1678-4324 Online Edition

AN INTERNATIONAL JOURNAL

\title{
Evaluation of Two Fitting Methods Applied for Thin-Layer Drying of Cape Gooseberry Fruits
}

\author{
Erkan Karacabey ${ }^{1}$. \\ ${ }^{1}$ Suleyman Demirel Universitesi - Food Engineering Department, Süleyman Demirel University Engineering \\ Faculty Food Engineering Department, Turkey.
}

\begin{abstract}
Drying data of cape gooseberry was used to compare two fitting methods: namely 2-step and 1-step methods. Literature data was also used to confirm the results. To demonstrate the applicability of these methods, two primary models (Page, Two-term-exponential) were selected. Linear equation was used as secondary model. As well-known from the previous modelling studies on drying, 2-step method required at least two regressions: One is primary model and one is secondary (if you have only one environmental condition such as temperature). On the other hand, one regression was enough for 1-step method. Although previous studies on kinetic modelling of drying of foods were based on 2-step method, this study indicated that 1-step method may also be a good alternative with some advantages such as drawing an informative figure and reducing time of calculations.
\end{abstract}

Key words: 1-step \& 2-step method; kinetic modelling; Page model; Two-term exponential model; food processing aspects

\footnotetext{
*Author for correspondence: erkankaracabey@sdu.edu.tr
} 


\section{INTRODUCTION}

Controlling the moisture content under critical level which inhibits and/or slows down the biochemical and microbiological activities is one of the easiest ways for food preservation. One of them is drying, being a thermal treatment applied by manufacturers to a large extent of fresh food materials to improve their shelf-lives, since fresh food material is open to microbial spoilage and undesirable biochemical changes ${ }^{1}$. High interest towards fruits is related to their functional properties affecting and preventing human health against some diseases ${ }^{2}$. Thus, drying processes gain high importance ${ }^{3}$. Cape gooseberry (Physalisperuviana L.) belonging to Solanaceae family has been reported to appear in the treatments against diseases including cancer, malaria, asthma, hepatitis, dermatitis and rheumatism ${ }^{4,5}$. Health benefits of this fruit are primarily associated with its nutritional composition and biologically active components ${ }^{6-}$

10. Important nutritional properties as well as medicinal properties make cape gooseberry as an attractive fruit in international markets ${ }^{11}$.

Mathematical modelling is frequently appealed way to predict the change of water content throughout the food material during dehydration processes. In literature, there are plenty number of kinetic studies about dehydration of different type of food materials and in these works, different types of equation have been proposed ${ }^{1,3,12-14}$. In these studies, 2-step method was used as a common technique for kinetic analysis. This study considers kinetic analysis of drying process from different point of view. Unlike generally reported studies, 1-step method was examined and its performance was compared with 2-step method, the pros and cons were summarized.

There are plenty number of studies (mostly about microbial survival under the effect of thermal and non-thermal processes) looking for the best methodology to describe the experimental data sets and they have announced that the 1-step method is better than the 2-step one $e^{15-17}$. Arabshahi and Lund ${ }^{18}$ and Haralampu et al. ${ }^{19}$ showed that the 1 -step method gave smaller confidence intervals for the coefficients than the 2-step method. Bréand et al. ${ }^{20}$ and Fernández et al. ${ }^{21}$ also concluded that the 1-step method gave more precise coefficient estimates, so "What is the reason for substantive use of the 2-step method for model fitting?" The answer is given as "a habit" by Jewell 1 . Similar behavior is seen in the kinetic studies of drying processes for food materials. To the best of author's knowledge, no study has been reported to compare these two fitting methods to estimate the drying data of foods. Only, Chenlo et al. ${ }^{22}$ have used the global kinetic modelling in which the main variables of osmotic dehydration process such as temperature, osmotic concentration and operation time were taken into account and their effects on the effective moisture diffusivity were considered.

The main objective of the present study was to introduce another kinetic analysis method (1-step method) for dehydration of food materials and to take interests of studies towards this technique. For this purpose cape gooseberry fruits were subjected to thin layer conventional oven drying. To figure out the working performance of this technique available drying data in literature were also used. As a primary model two common equations in literature were studied.

\section{MATERIAL AND METHODS}

\section{Material}

Cape gooseberry was purchased from local producer in Antalya, Turkey, and stored at $4^{\circ} \mathrm{C}$ until use. The calyx was removed, and fruit was washed before drying.

\section{Drying Process}

Drying experiments, performed in triplicate, were carried out at three temperatures $(60,70$, and $80^{\circ} \mathrm{C}$ ), employing a constant air flow of $1.3 \pm 0.02$ $\mathrm{m} / \mathrm{s}$ (perpendicular direction to sample). Cape gooseberry samples (mean diameter of $1.69 \pm 0.033$ $\mathrm{cm})$ were dried as a thin layer within a stainless steel basket with a load density of $1.6 \pm 0.04 \mathrm{~kg} / \mathrm{m}^{2}$. The weight change of drying berries was monitored and recorded as a function of process time. The moisture ratio is defined as shown below (Eq. 1);

$M R=\frac{\left(M_{t}-M_{e}\right)}{\left(M_{0}-M_{e}\right)}$

Where $M_{t}$ is the moisture content of drying material at any time, $t ; M_{o}$ is the initial moisture content of drying material $(t=0) ; M_{e}$ is the equilibrium moisture content $(\mathrm{t} \rightarrow \infty)$. However, in literature it was simplified to $M_{t} / M_{0}$, since $M_{e}$ is relatively small compared to $M_{t}$ and $M_{o}$ and accepted to be negligible ${ }^{23-25}$. 


\section{Two-Step Method}

In this method, the experimental drying data of moisture change with time is fitted firstly to a primary model. Regression analysis gives the calculated primary model's parameters as well as goodness-of-fit. Then, these calculated primary model's parameters are defined as a function of any environmental condition (temperature) in a secondary model.

\section{Primary models}

As the primary models, Page and two-termexponential were the governing equations, since they are the popular models to describe the change in the moisture ratio (MR) of solid matrix under isothermal conditions with time due to their simplicities and high prediction performances ${ }^{26,27}$. Page $^{28}$ modified the Lewis model to get a more accurate model by adding a dimensionless empirical constant (n) and apply to the mathematical modelling of drying of shelled corns (Eq. 2):

$$
M_{t} /_{M_{0}}=\exp \left(-k_{1} t^{n}\right)
$$

$M_{0}$ is the initial moisture content of drying material. $M_{\mathrm{t}}$ is the moisture ratio at any time. $t$ is drying time. $k_{1}\left(\mathrm{~s}^{-\mathrm{n}}\right.$ for dehydration data of cape gooseberry or $\mathrm{h}^{-\mathrm{n}}$ for dehydration data of rose pin reported by Ochoa et al. $^{29}$ ) is drying constant. Generally, $n$ (dimensionless) is named as the model constant.

Sharaf-Eldeen et al. ${ }^{30}$ modified the two-term model by reducing the constant number and organizing the second exponential term's indication of shape constant $(b)$. They emphasized that $b$ of the two-term model has to be $(1-a)$ at $t$ $=0$ to get $\mathrm{MR}=1$ and proposed a modification as (Eq. 3):

$$
M_{t} /_{M_{0}}=\operatorname{aexp}\left(-k_{2} t\right)+(1-a) \exp \left(-a k_{2} t\right)
$$

where, $a$ (dimensionless) is defined as the indication of shape and generally named as model constant. $\mathrm{k}_{2}\left(\mathrm{~s}^{-1}\right.$ for dehydration data of cape gooseberry or $\mathrm{h}^{-1}$ for dehydration data of rose pin reported by Ochoa et al. ${ }^{29}$ ) is the drying constants. Secondary model
A secondary model describes primary model parameters as a function of other variables, usually environmental conditions of drying process such as temperature and/or air flow velocity. This work is restricted to conditions not changing with time, but the principles apply more generally. Although there are different mathematical expressions are available as a secondary model, linear form could be the best choice for some cases. For the case (having only data for three temperature levels) like in this study, fitting any mathematical equation different than linear one to the calculated primary model parameters needs more data to reliably explain the relation. Otherwise fitting higher order equation or nonlinear forms like exponential, logarithmic etc. to insufficient data points is sure to give any model with coefficients, but it is not obvious to work precisely. In current study, linear form of temperature was used to explain the changes in parameters of Page and two-term exponential models, since primary models fitted to the experimental data were obtained only at three temperature levels. Parameters of the Page model were described by the following linear equations (Eqs. 4 and 5):

$k_{1}(T)=C_{1}+C_{2} \cdot T$

$n(T)=C_{3}+C_{4} \cdot T$

where $C_{i}$, are the coefficients of secondary model and $T\left({ }^{\circ} \mathrm{C}\right)$ is the drying temperature.

Parameters of the two-term exponential model were described by the following linear equations (Eqs. 6, 7):

$a(T)=C_{5}+C_{6} \cdot T$

$k_{2}(T)=C_{7}+C_{8} \cdot T$

where again $C_{\mathrm{i}}$, are the coefficients of secondary model and $T\left({ }^{\circ} \mathrm{C}\right)$ is the drying temperature.

\section{One-Step Method}

In this method, main objective is to define the change of moisture content with time and any other variable(s) in a single equation called as "global model".

In principle, although it may be difficult in practice, secondary model can always be substituted into primary model to achieve a global model. 
In current study, temperature (being the only environmental condition) was included in global model addition to time variable, so global form of Page model was defined such that its parameters $k_{1}$ and $n$ were explained as a function of temperature. If Eqs. (4) and (5) are integrated into Eq. (2), it takes the following form (Eq. 8):

$$
M_{t} /_{M_{0}}=\exp \left\{-\left[C_{1}+C_{2} T\right] t^{\left(C_{3}+C_{4} T\right)}\right\}
$$

To produce a global form of two-term exponential model, Eqs. (6) and (7) are integrated into Eq. (3) and it takes the following form (Eq. 9):

$$
\begin{aligned}
& M_{t} / M_{0}=\left(C_{5}+C_{6} T\right) \exp \left[-\left(C_{7}+C_{8} T\right) t\right]+ \\
& {\left[1-\left(C_{5}+C_{6} T\right)\right] \exp \left\{-\left(C_{5}+C_{6} T\right)\left(C_{7}+\right.\right.} \\
& \text { C8Tt }
\end{aligned}
$$

Fitting of The Equations and Data Analysis

The drying curve of cape gooseberry was produced experimentally at three different temperatures $\left(60,70\right.$ and $\left.80{ }^{\circ} \mathrm{C}\right)$ and a constant air velocity $(1.3 \mathrm{~m} / \mathrm{s})$, so temperature was the sole environmental condition in this case. Rossello et al. ${ }^{31}$ reported that above certain flow value (1-1.5 $\mathrm{m} / \mathrm{s}$ ), air flow rate has no effect on the mass flux, so the flow value assigned in this work can be accepted as high enough to neglect the effect of external mass resistance.

Published data were obtained from literature reported by Ochoa et al. ${ }^{29}$ who studied a thin layer whole rose pin drying process conducted at the drying air temperature of 50,60 and $70{ }^{\circ} \mathrm{C}$ and air velocity of $1.0 \mathrm{~m} / \mathrm{s}$. Relative humidity of drying air was $50 \%$. For data mining, Plot Digitizer (Freeware, 2.6.6, 2014) was used.

For each data set, both fitting methods were applied:

\section{2-step method}

i) primary model(s) [Eqs. (2) (Page) and (3) (Twoterm exponential)] fitted separately to data from each drying trial at different conditions.

ii) secondary model(s) [Eqs. (4), (5) for Page and (6), (7) for Two-term exponential] for each primary model parameter fitted separately to results of first step. 1-step method

iii) global model(s) [Eqs. (8) (global form of Page) and (9) (global form of two-term exponential)] fitted to data from all trials at once.

SigmaPlot 12.0 (Systat Software Inc., San Jose, CA, USA) was used for nonlinear regression analysis. The goodness-of-fit of each model was assessed using the adjusted determination coefficient $\left(\mathrm{R}_{\text {adj }}{ }^{2}\right)$ and mean square error (MSE).

\section{RESULTS AND DISCUSSION}

\section{Model Fitting by 2-Step Method}

Drying of cape gooseberry fruit was carried out at temperature level of 60,70 and $80{ }^{\circ} \mathrm{C}$ under constant air flow velocity of $1.3 \mathrm{~m} / \mathrm{s}$. Drying curves obtained at each temperature level in this study and those reported by Ochoa et al..$^{29}$, and fits of Page and two-term-exponential models were shown in Figure 1. Nonlinear regression analysis was performed by following 2-step method. Table 1 displays the model parameters and prediction performance. As can be seen in Table 1, both models produced reasonable goodness-of-fit $\left(\mathrm{R}_{\text {adj }}^{2}>0.99, \quad M S E<10^{-3}\right)$. Estimated model parameters of Page model and two-term exponential model were also given in Table 1 . Figure 2A, 2B and Figure 3A, 3B showed the temperature dependency of primary model parameters calculated for Page and two-term exponential models, respectively. Linear equation was used to explain the change of primary model's parameters with temperature, instead of other possible equation forms (exponential, logarithmic, etc.). Because more temperature levels than that $\left(60^{\circ} \mathrm{C}, 70^{\circ} \mathrm{C}\right.$, and $\left.80^{\circ} \mathrm{C}\right)$ were studied in this study are required to precisely explain the temperature dependency of these parameters using other mathematical expressions. Figure $2 \mathrm{~A}$ and $2 \mathrm{~B}$ indicate that the current study generally worked well with linear form. However, poor fits with linear equations were obtained for some parameters (Fig. 2B) and also for some data of Ochoa et al. ${ }^{29}$,- data not shown. However, these poor fittings had little consequence on the goodness-of-fit of the 1-step method - see below.

Table 1. Parameters of primary models estimated by nonlinear regression and model performance values 
Comparison of two fitting methods

\begin{tabular}{|c|c|c|c|}
\hline & $\begin{array}{l}\text { Drying } \\
\text { temperature }\end{array}$ & Page & Two-term-exponential \\
\hline $\begin{array}{l}\text { D. } \\
0 \\
0 \\
0 \\
0 \\
0 \\
0\end{array}$ & $60{ }^{\circ} \mathrm{C}$ & $\begin{array}{l}k_{1}=7 \times 10^{-4} \pm 6.2 \times 10^{-5} \\
n=1.35 \pm 0.02 \\
\mathrm{R}_{\text {adj }}^{2}=0.9993 \\
M S E=5.9 \times 10^{-5}\end{array}$ & $\begin{array}{l}k_{2}=6.8 \times 10^{-3} \pm 7 \times 10^{-5} \\
a=1.89 \pm 0.01 \\
\mathrm{R}_{\text {adj }}^{2}=0.9993 \\
M S E=5.3 \times 10^{-5}\end{array}$ \\
\hline $\begin{array}{l}0 \\
0 \\
0 \\
0 \\
\text { U. } \\
0\end{array}$ & $70{ }^{\circ} \mathrm{C}$ & $\begin{array}{l}k_{1}=7 \times 10^{-4} \pm 5.4 \times 10^{-5} \\
n=1.48 \pm 0.02 \\
\mathrm{R}_{\text {adj }}^{2}=0.9997 \\
M S E=5.5 \times 10^{-5}\end{array}$ & $\begin{array}{l}k_{2}=1.27 \times 10^{-2} \pm 2 \times 10^{-4} \\
a=1.99 \pm 0.02 \\
\mathrm{R}_{\text {adj }}^{2}=0.9990 \\
M S E=2 \times 10^{-4}\end{array}$ \\
\hline 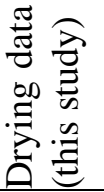 & $80{ }^{\circ} \mathrm{C}$ & $\begin{array}{l}k_{1}=5 \times 10^{-4} \pm 1 \times 10^{-4} \\
n=1.65 \pm 0.06 \\
\mathrm{R}_{\text {adj }}^{2}=0.9946 \\
M S E=4 \times 10^{-4}\end{array}$ & $\begin{array}{l}k_{2}=1.57 \times 10^{-2} \pm 7 \times 10^{-4} \\
a=2.03 \pm 0.05 \\
\mathrm{R}_{\text {adj }}^{2}=0.9891 \\
M S E=9 \times 10^{-4}\end{array}$ \\
\hline 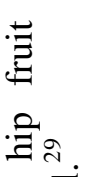 & $50{ }^{\circ} \mathrm{C}$ & $\begin{array}{l}k_{1}=0.064 \pm 0.006 \\
n=0.71 \pm 0.03 \\
\mathrm{R}_{\text {adj }}^{2}=0.9890 \\
M S E=2 \times 10^{-4}\end{array}$ & $\begin{array}{l}k_{2}=0.21 \pm 0.19 \\
a=0.11 \pm 0.08 \\
\mathrm{R}_{\text {adj }}^{2}=0.9804 \\
M S E=4 \times 10^{-4}\end{array}$ \\
\hline 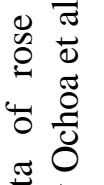 & $60{ }^{\circ} \mathrm{C}$ & $\begin{array}{l}k_{1}=0.23 \pm 0.011 \\
n=0.90 \pm 0.025 \\
\mathrm{R}_{\text {adj }}^{2}=0.9969 \\
M S E=3 \times 10^{-4}\end{array}$ & $\begin{array}{l}k_{2}=0.35 \pm 0.049 \\
a=0.40 \pm 0.055 \\
\mathrm{R}_{\text {adj }}^{2}=0.9974 \\
M S E=2 \times 10^{-4}\end{array}$ \\
\hline 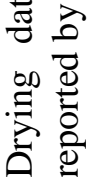 & $70{ }^{\circ} \mathrm{C}$ & $\begin{array}{l}k_{1}=0.44 \pm 0.02 \\
n=0.83 \pm 0.03 \\
\mathrm{R}_{\text {adj }}^{2}=0.9970 \\
M S E=2 \times 10^{-4}\end{array}$ & $\begin{array}{l}k_{2}=1.83 \pm 0.65 \\
a=0.16 \pm 0.050 \\
\mathrm{R}_{\text {adj }}^{2}=0.9977 \\
M S E=2 \times 10^{-4}\end{array}$ \\
\hline
\end{tabular}

Model Fitting by 1-Step Method

One-step method was studied as an alternative way to 2-step one for the kinetic evaluation of drying process. Drying data set of cape gooseberry, described with models using 2-step method, was analyzed by 1-step method. Global form of Page (Eq. 8) and two-term exponential (Eq.9) equations including temperature term addition to time variable were used in 1-step method. Goodness of fit parameters $\left(\mathrm{R}_{\mathrm{adj}}{ }^{2}\right.$ and $\left.M S E\right)$ and calculated model coefficients were given in Table 2 . The produced global models are function of time and temperature, so Figure $4 \mathrm{~A}$ and $4 \mathrm{~B}$, respectively, corresponding to Page and two-term exponential models were drawn to present time and temperature dependency of moisture ratio of cape gooseberry. Temperature influence on the change in moisture ratio of cape gooseberry fruits during drying could be seen in Figure 4A and 4B. Moisture ratio decreases with increasing temperature level, when same time line is considered. Additionally, slope of surface changes to more vertical than horizontal with rise in drying temperature, which is especially clear in Figure
4A. Another point indicating temperature effect is final part of surface. Final part is almost horizontal when higher temperature is selected. In other words, moisture ratio reached earlier to its lowest, when higher temperature is preferred (Fig. 4A and 4B). Similar temperature effect on moisture ratio seen in Figure 4A and 4B was also observed for whole rose hip fruits (Fig. 5A and 5B). 
Table 2. Coefficients of global page and two-term exponential models

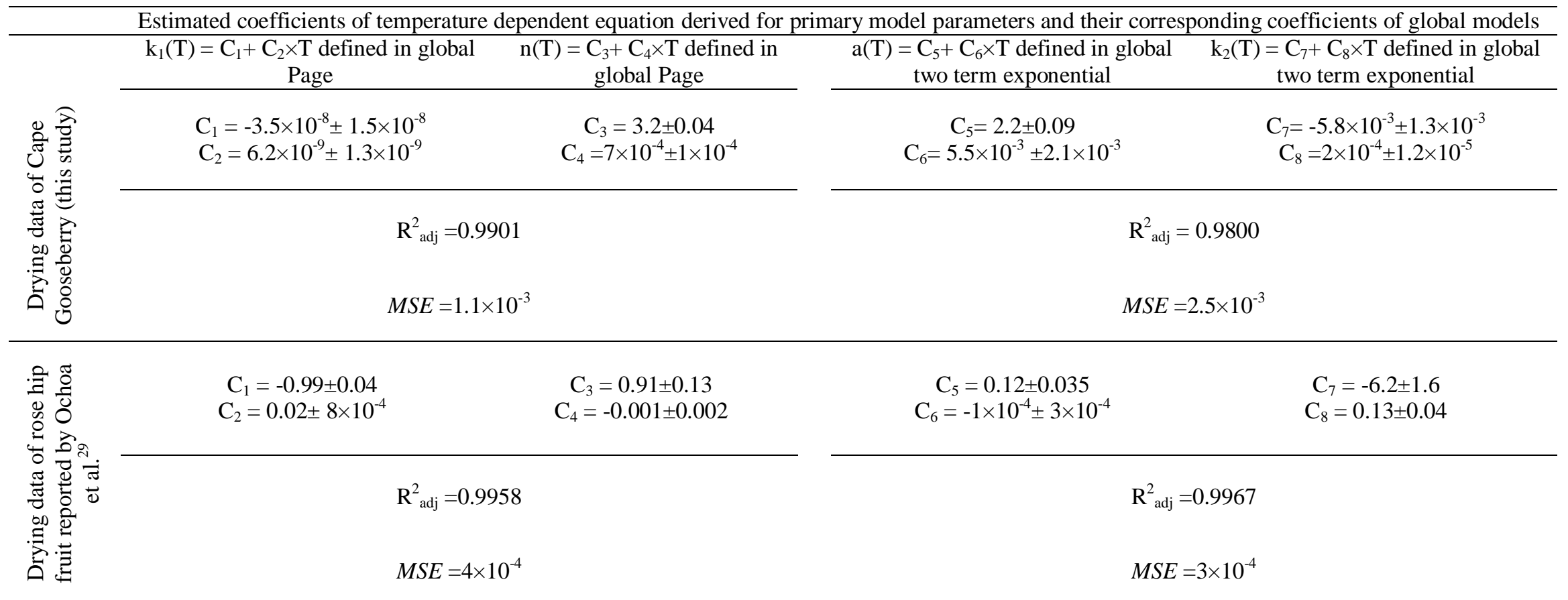

T: temperature, $\mathrm{C}_{1}-\mathrm{C}_{8}$ are model coefficients estimated directly by 1-step method 


\section{Comparison of Two Fitting Methods}

Main objective of the current study is to compare fitting methods: 1-step and 2-step, latter one is the common technique used in the kinetic analysis of drying process reported in literature ${ }^{26,27}$. For the 1step method, it is intended to govern an equation which should include the effect(s) of environmental condition(s) addition to time variable. As mentioned before, temperature is one of the important environmental conditions controlled during drying process. Thus, in this study, Page and two-term exponential equation were reformed to adapt to 1-step method. As a result they had one more variable addition to time, which was temperature. For 2-step method, time was the main variable of primary models. Linear functions were proposed to define the temperature dependency of model parameters, in other words indirect effect of temperature on drying was considered in second step of this method. Although determination coefficient values obtained in the regression analysis of 1-step method are slightly lower than those calculated for the primary models in the first step of 2-step method, it should be taken into account that the global model obtained by 1-step method calculates simultaneously both temperature and time effects and produces more information in one calculation step (Table 1 and 2). Another advantage of 1-step method compared to 2-step one is the time requirement for calculation. It is clear that 1-step requires only one regression analysis to explain the effects of both (time and temperature) variables, whereas three regressions need to be carried for 2step method. Additionally, change in moisture ratio of drying material with temperature and time could be shown in one $3 \mathrm{D}$ figure, which is drawn using one global model (Fig. 4A, 4B for global forms of Page and two-term exponential models, respectively, proposed for cape gooseberry drying and Fig. 5A, 5B global forms of Page and twoterm exponential models, respectively, proposed for literature data reported by Ochoa et $\mathrm{al}^{29}$ ). However, at least two or more figures are required to describe the variation of moisture ratio with time and temperature in 2-step method (Fig. 1A, $1 \mathrm{~B}, 2 \mathrm{~A}, 2 \mathrm{~B}, 3 \mathrm{~A}$, and $3 \mathrm{~B})$. Considering these advantages, 1-step method could be suggested for the evaluation of drying process from the point of kinetic analysis.

\section{CONCLUSION}

As a conclusion, it could be said that 1-step method produces a global model which includes more variables addition to time affecting moisture ratio change in drying of food materials, so it produces valuable information about environmental conditions, however those could be taken into account only if at the second step of 2step method. On the other hand, saving time is obvious since only one regression is enough for the evaluation of the effects of all variables on moisture ratio change. In other words it can be said that 1-step method could be considered in the kinetic analysis, although its usage is not common in drying processes, so more information produces without making more effort.
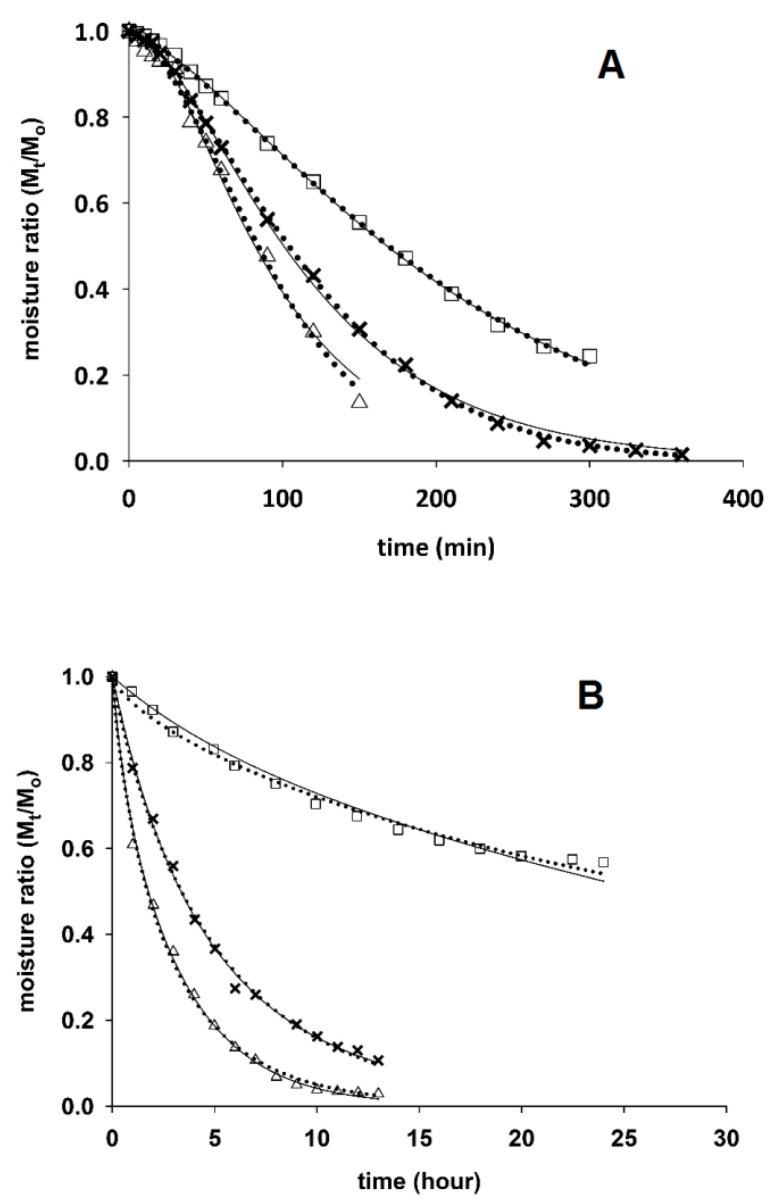

Figure 1. Moisture ratio change of drying cape gooseberry at temperature of $(\square) 60^{\circ} \mathrm{C},(\times) 70{ }^{\circ} \mathrm{C}$, and (A) $80^{\circ} \mathrm{C}$. (A); Moisture ratio change of drying whole rose hip 26 at temperature of $(\square) 50^{\circ} \mathrm{C},(\times) 60{ }^{\circ} \mathrm{C}$, and $(\Delta) 70^{\circ} \mathrm{C}(\mathrm{B})$. Curves of fitted ( $\left.\cdots\right)$ Page model and (一) two-term exponential model by 2 -step method. 

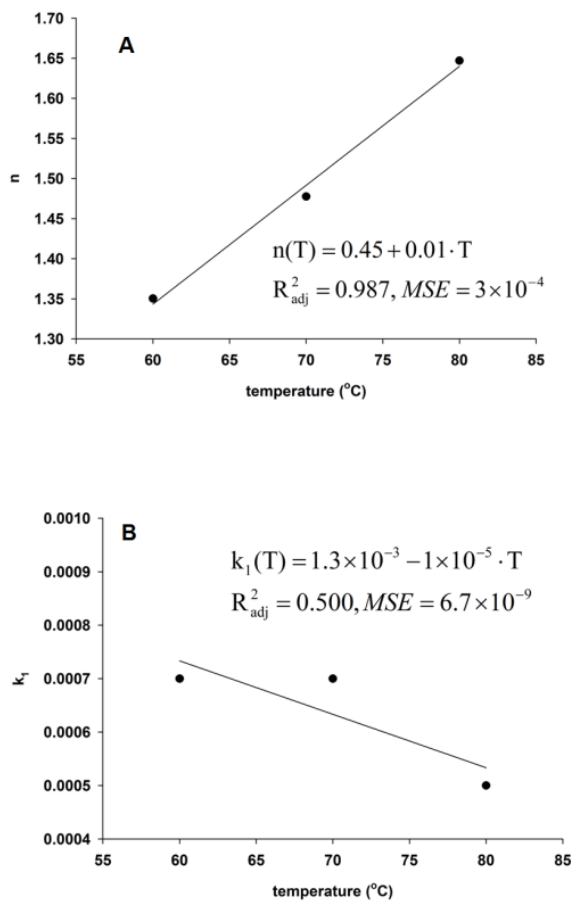

Figure 2. Temperature dependence of parameters of Page model fitted to cape gooseberry drying data in the first step of 2-step method and linear regression analysis; $n$ value $(\mathrm{A}), \mathrm{k} 1$ value (B).
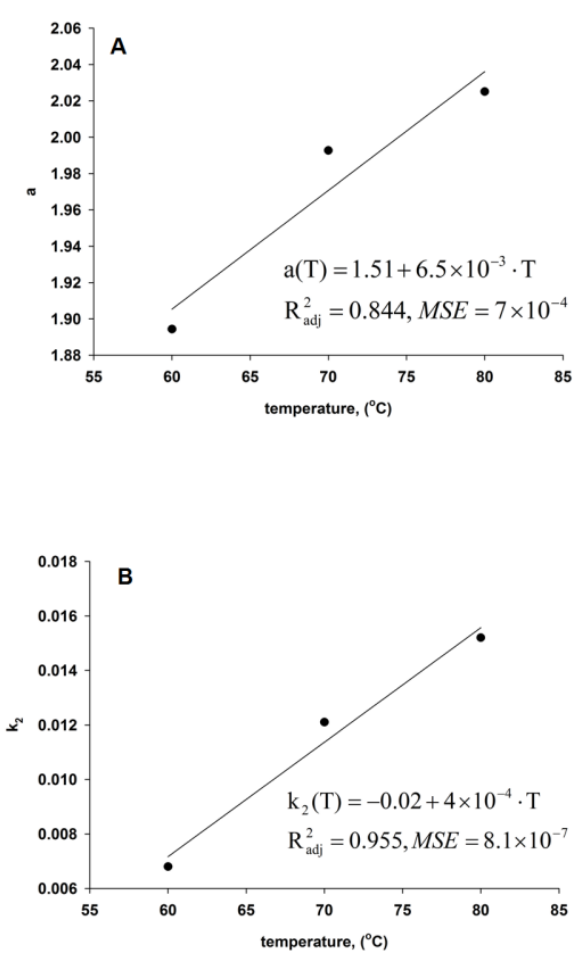

Figure 3. Temperature dependence of parameters of two-term exponential model fitted to cape gooseberry drying data in the first step of 2-step method and linear regression analysis; a value $(\mathrm{A}), \mathrm{k} 2$ value $(\mathrm{B})$.
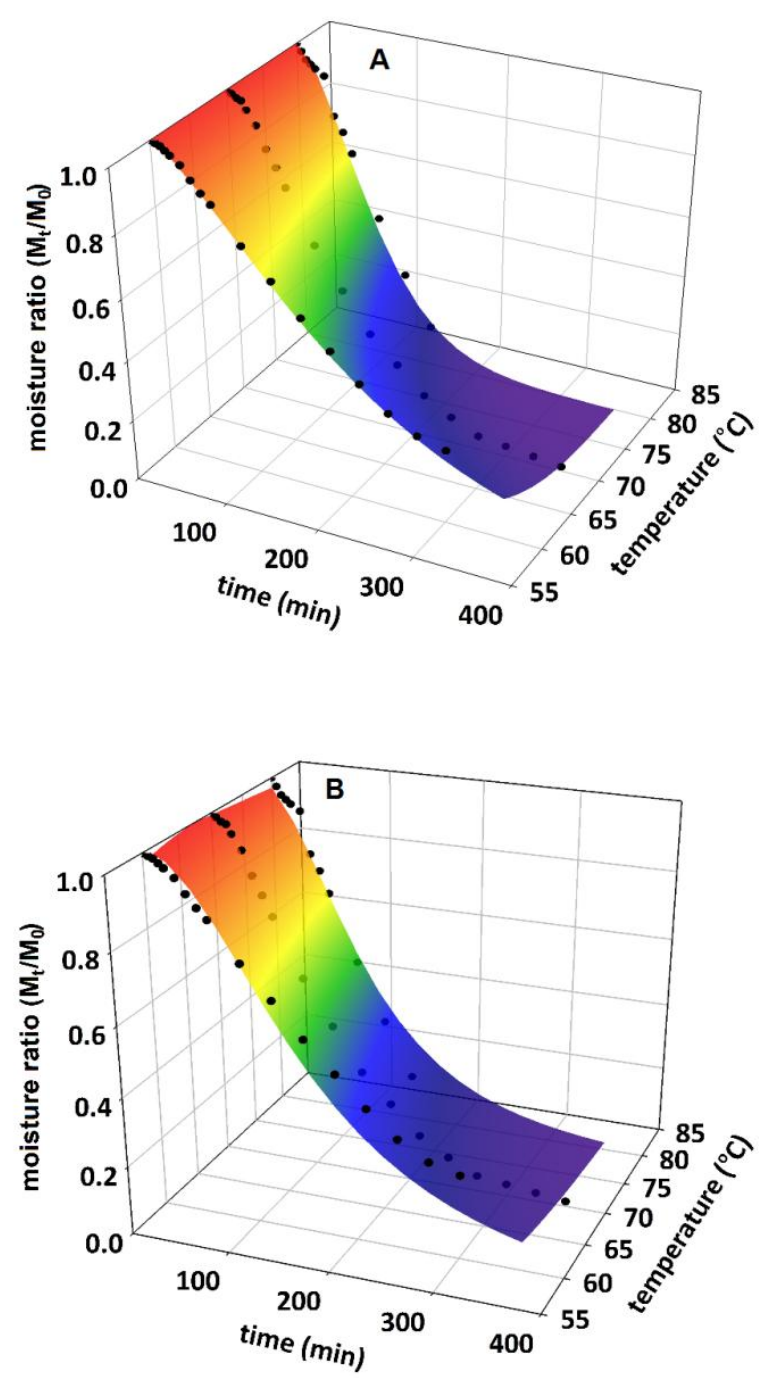

Figure 4. Experimental moisture ratio values $(\bullet)$ of cape gooseberry dried at different time and temperature. Surface represents the fitted global model of Page (A) and two-term exponential (B) using 1-step method. 

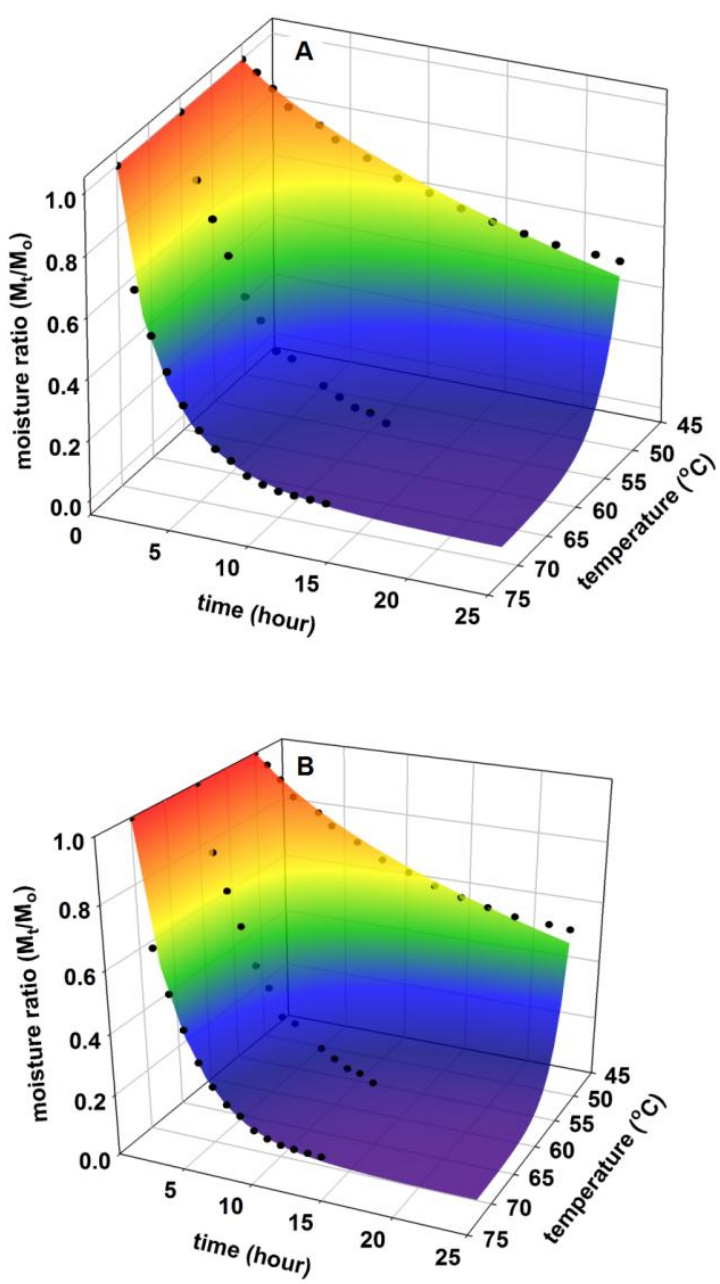

Figure 5. Moisture ratio values $(\bullet)$ of whole rose pin dried at different time and temperature 26. Surface represents the fitted global model of Page (A) and twoterm exponential (B) using 1-step method.

\section{REFERENCES}

1. Esturk, O. Intermittent and Continuous MicrowaveConvective Air-Drying Characteristics of Sage (Salvia officinalis) Leaves. Food Bioprocess Tech 2012; 5: 1664-1673.

2. Zhao, Y. Berry fruit: value-added products for health promotion. CRC Press; 2007.

3. Doymaz, İ., Demir, H., and Yildirim, A. Drying of Quince Slices: Effect of Pretreatments on Drying and Rehydration Characteristics. Chem Eng Commun 2015; 202: 1271-1279.

4. Salazar, M.R., Jones, J.W., Chaves, B., and Cooman, A. A model for the potential production and dry matter distribution of Cape gooseberry (Physalis peruviana L.). Sci Hort 2008; 115: 142148.

5. Ramadan, M.F., and Moersel, J.T. Impact of enzymatic treatment on chemical composition, physicochemical properties and radical scavenging activity of goldenberry (Physalis peruviana L.) juice. J Sci Food Agric 2007; 87: 452-460.

6. Ramadan, M.F., and Moersel, J.-T. Oil extractability from enzymatically treated goldenberry (Physalis peruviana L.) pomace: range of operational variables. Int J Food Sci Tech 2009; 44: 435-444.

7. Ramadan, M.F., Sitohy, M.Z., and Moersel, J.-T. Solvent and enzyme-aided aqueous extraction of goldenberry (Physalis peruviana L.) pomace oil: impact of processing on composition and quality of oil and meal. Eur Food Res Technol 2008; 226: 1445-1458.

8. Ramadan, M.F. Bioactive phytochemicals, nutritional value, and functional properties of cape gooseberry (Physalis peruviana): An overview. Food Res Int 2011; 44: 1830-1836.

9. Ramadan, M.F., and Mörsel, J.-T. Oil Goldenberry (Physalis peruviana L.). J Agric Food Chem 2003; 51: 969-974.

10. McCain, R. Goldenberry, passionfruit and white sapote: potential fruits for cool subtropical areas. In: J. Janick and J.E. Simon. New Crops. New York: Wiley \& Sons; 1993. 479-486.

11. Erkaya, T., Dağdemir, E., and Şengül, M. Influence of Cape gooseberry (Physalis peruviana L.) addition on the chemical and sensory characteristics and mineral concentrations of ice cream. Food Res Int 2012; 45: 331-335.

12. Midilli, A., Kucuk, H., and Yapar, Z. A new model for single-layer drying. Drying Technol 2002; 20: 1503-1513.

13. Thorat, I., Mohapatra, D., Sutar, R.F., Kapdi, S.S., and Jagtap, D. Mathematical Modeling and Experimental Study on Thin-Layer Vacuum Drying of Ginger (Zingiber Officinale R.) Slices. Food Bioprocess Tech 2012; 5: 1379-1383.

14. Arslan, D., and Özcan, M. Evaluation of Drying Methods with Respect to Drying Kinetics, Mineral Content, and Color Characteristics of Savory Leaves. Food Bioprocess Tech 2012; 5: 983-991.

15. Chen, G. A comparison of two methods for estimating microbial survival parameters from dynamic survival data. Int J Food Sci Tech 2013; 48: 1109-1113.

16. Jewell, K. Comparison of 1-step and 2-step methods of fitting microbiological models. Int $J$ Food Microbiol 2012; 160: 145-161.

17. Fernández, A., Collado, J., Cunha, L.M., Ocio, M.J., and Martínez, A. Empirical model building based on Weibull distribution to describe the joint effect of $\mathrm{pH}$ and temperature on the thermal resistance of Bacillus cereus in vegetable substrate. Int J Food Microbiol 2002; 77: 147-153. 
18. Arabshahi, A., and Lund, D.B. Considerations in calculating kinetic parameters from experimental data. J Food Process Eng 1985; 7: 239-251.

19. Haralampu, S.G., Saguy, I., and Karel, M. Estimation of Arrhenius model parameters using three least squares methods. J Food Process Preserv 1985; 9: 129-143.

20. Bréand, S., Fardel, G., Flandrois, J.P., Rosso, L., and Tomassone, R. A model describing the relationship between regrowth lag time and mild temperature increase for Listeria monocytogenes. Int J Food Microbiol 1999; 46: 251-261.

21. Fernández, A., Ocio, M.J., Fernández, P.S., Rodrigo, M., and Martinez, A. Application of nonlinear regression analysis to the estimation of kinetic parameters for two enterotoxigenic strains ofBacillus cereus spores. Food Microbiol 1999; 16: 607-613.

22. Chenlo, F., Moreira, R., Fernández-Herrero, C., and Vázquez, G. Osmotic dehydration of chestnut with sucrose: Mass transfer processes and global kinetics modelling. J Food Eng 2007; 78: 765-774.

23. Doymaz, İ. Convective air drying characteristics of thin layer carrots. J Food Eng 2004; 61: 359-364.

24. Ertekin, C., and Yaldiz, O. Drying of eggplant and selection of a suitable thin layer drying model. $J$ Food Eng 2004; 63: 349-359.

25. Doymaz, I., Kipcak, A.S., and Piskin, S. Characteristics of Thin-layer Infrared Drying of Green Bean. Czech J Food Sci 2015; 33: 83-90.

26. Kucuk, H., Midilli, A., Kilic, A., and Dincer, I. A Review on Thin-Layer Drying-Curve Equations. Drying Technol 2014; 32: 757-773.

27. Erbay, Z., and Icier, F. A Review of Thin Layer Drying of Foods: Theory, Modeling, and Experimental Results. Crit Rev Food Sci Nutr 2010; 50: 441-464.

28. Page, G. (1949). Factors Influencesing The Maximum Rates of Air Drying Shelled Corn in Thin Layers. M.S., Purdue University.

29. Ochoa, M.R., Kesseler, A.G., Pirone, B.N., Márquez, C.A., and De Michelis, A. Shrinkage During Convective Drying of Whole Rose Hip (Rosa Rubiginosa L.) Fruits. LWT - Food Sci Technol 2002; 35: 400-406.

30. Sharaf-Eldeen, Y., Blaisdell, J., and Hamdy, M. A model for ear-corn drying. Trans ASAE 1980; 23: 1261-1265, 1271.

31. Rossello, C., Canellas, J., Simal, S., and Berna, A. Simple mathematical model to predict the drying rates of potatoes. J Agric Food Chem 1992; 40: 2374-2378.

Received: February 03, 2016; Accepted: July 14, 2016 